This article was downloaded by: [University of Malaya]

On: 02 January 2014, At: 09: 08

Publisher: Taylor \& Francis

Informa Ltd Registered in England and Wales Registered Number: 1072954 Registered office: Mortimer House, 37-41 Mortimer Street, London W1T 3J H, UK

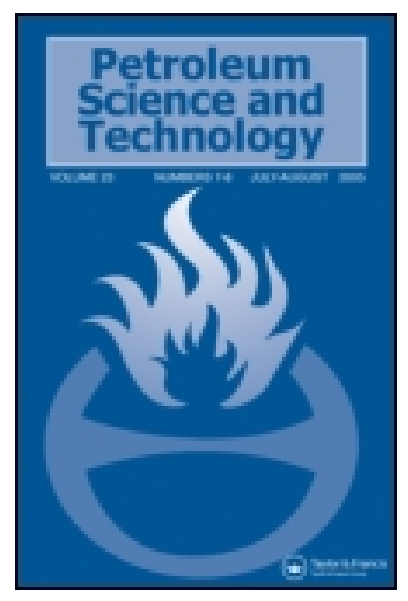

Petroleum Science and Technology

Publication details, including instructions for authors and subscription information:

http:/ / www. tandfonline.com/ loi/ lpet20

\title{
The Viscosity of Nontraditional Lightweight Completion Fluid at Elevated Temperature and Pressure
}

\author{
M. Khalil ${ }^{\text {a }}$, B. M. J an ${ }^{a} \&$ A. A. A. Raman ${ }^{a}$ \\ ${ }^{a}$ Department of Chemical Engineering, Faculty of Engineering, \\ University of Malaya, Kuala Lumpur, Malaysia \\ Published online: 12 J ul 2012.
}

To cite this article: M. Khalil , B. M. Jan \& A. A. A. Raman (2012) The Viscosity of Nontraditional Lightweight Completion Fluid at Elevated Temperature and Pressure, Petroleum Science and Technology, 30:18, 1939-1945, DOI: 10.1080/ 10916466.2010.512887

To link to this article: http:// dx.doi.org/ 10.1080/ 10916466.2010.512887

\section{PLEASE SCROLL DOWN FOR ARTICLE}

Taylor $\&$ Francis makes every effort to ensure the accuracy of all the information (the "Content") contained in the publications on our platform. However, Taylor \& Francis, our agents, and our licensors make no representations or warranties whatsoever as to the accuracy, completeness, or suitability for any purpose of the Content. Any opinions and views expressed in this publication are the opinions and views of the authors, and are not the views of or endorsed by Taylor \& Francis. The accuracy of the Content should not be relied upon and should be independently verified with primary sources of information. Taylor and Francis shall not be liable for any losses, actions, claims, proceedings, demands, costs, expenses, damages, and other liabilities whatsoever or howsoever caused arising directly or indirectly in connection with, in relation to or arising out of the use of the Content.

This article may be used for research, teaching, and private study purposes. Any substantial or systematic reproduction, redistribution, reselling, loan, sub-licensing, systematic supply, or distribution in any form to anyone is expressly forbidden. Terms \& Conditions of access and use can be found at http://www.tandfonline.com/page/termsand-conditions 


\title{
The Viscosity of Nontraditional Lightweight Completion Fluid at Elevated Temperature and Pressure
}

\author{
M. KHALIL, ${ }^{1}$ B. M. JAN, ${ }^{1}$ AND A. A. A. RAMAN ${ }^{1}$ \\ ${ }^{1}$ Department of Chemical Engineering, Faculty of Engineering, University of \\ Malaya, Kuala Lumpur, Malaysia
}

\begin{abstract}
Experimental viscosity values of nontraditional lightweight completion fluid at pressure and temperature ranges of $0.1 \mathrm{MPa}$ to $4.48 \mathrm{MPa}$, and of $25^{\circ} \mathrm{C}$ to $100^{\circ} \mathrm{C}$, respectively, were reported. To establish the relationship among viscosity, pressure, and temperature, experimental data were fit to the modification of Mehrotra and Svrcek's equation. The result shows that the model could be used to describe the fluid viscosity over a wide range of pressure and temperature. The calculated what is sum of square error and root mean square error are 0.2135 and 0.08892 , respectively. It is also shown that the predicted values from the model are in a good agreement with both the experimental values and field data.
\end{abstract}

Keywords completion fluid, high pressure-temperature, underbalance perforation, viscosity

\section{Introduction}

It is known that the use of nontraditional super lightweight completion fluid (SLWCF) during well completion improves well performances. A field test showed about an additional thousand barrels of oil was produced in a single day after the well was perforated with the nontraditional SLWCF (Badrul et al., 2009). SLWCF is attractive as it provides flexibility in having wide range of low fluid density. By perforating a well underbalance, it is possible to create a clean and undamaged perforation tunnel (Bartusiak et al., 1997). It is also reported that the use of nontraditional SLWCF to maintain the wellbore pressure lower than the formation pressure, results in a negative skin value and generating a minimum underbalance pressure difference of $0.84 \mathrm{MPa}$ (122 psi; Khalil et al., 2010). However, data of physical and chemical properties (e.g., rheological and thermodynamical properties) of SLWCF are scarce.

Viscosity is one of the most critical parameters in selecting an appropriate completion fluid. Viscosity profile as a function of temperature and pressure is very crucial. This study investigated viscosity profile of the nontraditional SLWCF at pressure and temperature ranges of $0.1-4.48 \mathrm{MPa}$ and $25-100^{\circ} \mathrm{C}$, respectively. These data were then fitted to the modification of Mehrotra and Svrcek (1987) equation to determine the viscosity profile as a function of pressure and temperature. The equation used to correlate the data can be expressed as follows:

$$
\ln (\mu)=\left(a_{1}+a_{2} \ln T\right)+a_{3} P
$$

Address correspondence to B. M. Jan, Department of Chemical Engineering, Faculty of Engineering, University of Malaya, 50603 Kuala Lumpur, Malaysia. E-mail: badrules@um.edu.my 
where $\mu$ is fluid viscosity ( $\mathrm{Pa} \cdot \mathrm{sec}), T$ is temperature $\left({ }^{\circ} \mathrm{C}\right)$, and $P$ is pressure (MPa). $a_{1}$, $a_{2}$, and $a_{3}$ are empirical constants in Eq. (1).

\section{Experimental}

\section{Formulation of the Nontraditional SLWCF}

The nontraditional SLWCF was prepared based on our previous study (Badrul et al., 2009). The fluid consists of Shell sarapar oil as continuous synthetic oil-based completion fluid, $3 \mathrm{M}$ hollow glass bubbles as a density reducing agent, an appropriate homogenizing and stabilizing agents. The amount of sarapar oil and glass bubbles was fixed at $65 \%$ and $35 \%$ by weight, respectively. However, the amount of homogenizing agent and stabilizing agent were fixed at $4 \%$ and $10 \%$ by weight, respectively. All of the raw materials were mixed using IKA T25 digital ultra-turrax disperser for $1 \mathrm{hr}$ at 14,000 rpm.

\section{Viscosity Measurement}

Fluid viscosity at elevated pressure and temperature were measured using a highpressure/high-temperature NI Rheometer model 5600 (Nordman Instruments, Inc., Houston, Texas). The measurement of SLWCF viscosity was conducted at pressure and temperature ranges of $0.1-4.48 \mathrm{MPa}$ and $25-100^{\circ} \mathrm{C}$, respectively. Nitrogen was used to compress the sample. Viscosity data at experimental range were then fitted to the modification of Mehrotra and Svrcek's (1987) equation using Matlab Version 7.9 (The MathWorks, Natick, Massachusetts). The three modifications of Mehrotra and Svrcek's equation parameter along with some statistical parameters were calculated using the same software.

\section{Results and Discussions}

Experimental viscosity values of the nontraditional SLWCF are presented in Table 1. Viscosity were measured at temperature and pressure ranges of $25-100^{\circ} \mathrm{C}$ and $0.1-$ 4.48 $\mathrm{MPa}$, respectively. The variation of the measured viscosity data as a function of temperature are shown in Figure 1. The variations of viscosity as a function of pressure are presented in Figure 2.

Table 1

Experimental viscosity $(\mu$; Pa.sec) of nontraditional lightweight completion fluid at various temperature $(T)$ and pressure $(P)$

\begin{tabular}{lcccccc}
\hline \multicolumn{7}{c}{$T,{ }^{\circ} \mathrm{C}$} \\
\hline$P, \mathrm{MPa}$ & 25 & 40 & 50 & 70 & 80 & 100 \\
\hline 0.1 & 0.19523 & 0.17993 & 0.12766 & 0.11059 & 0.09945 & 0.09534 \\
1.34 & 0.20722 & 0.19179 & 0.13859 & 0.11745 & 0.1054 & 0.09978 \\
2.06 & 0.21034 & 0.20085 & 0.15439 & 0.13248 & 0.11343 & 0.10654 \\
2.75 & 0.21635 & 0.21045 & 0.16408 & 0.14289 & 0.11976 & 0.11049 \\
4.48 & 0.23334 & 0.21924 & 0.1699 & 0.14646 & 0.13192 & 0.12534 \\
\hline
\end{tabular}




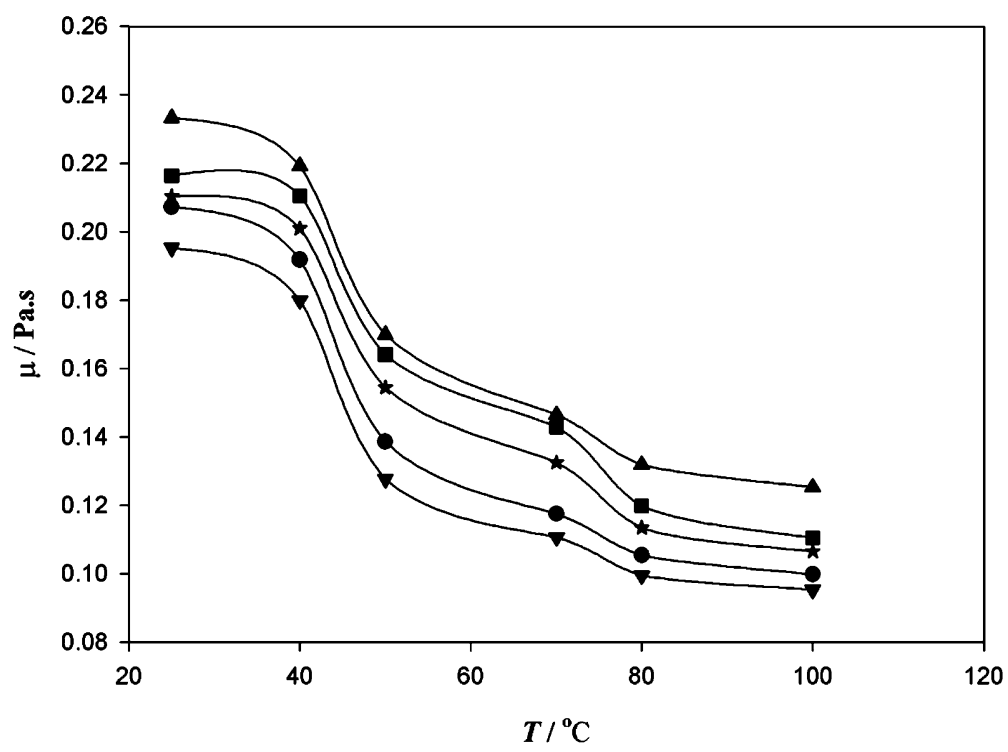

Figure 1. Experimental viscosity of nontraditional lightweight completion fluid as a function of temperature. $\boldsymbol{\nabla}=0.1 \mathrm{MPa} ; \boldsymbol{\bullet}=1.34 \mathrm{MPa} ; \star=2.06 \mathrm{MPa} ; \boldsymbol{\square}=2.75 \mathrm{MPa} ; \boldsymbol{\Delta}=4.48 \mathrm{MPa}$.

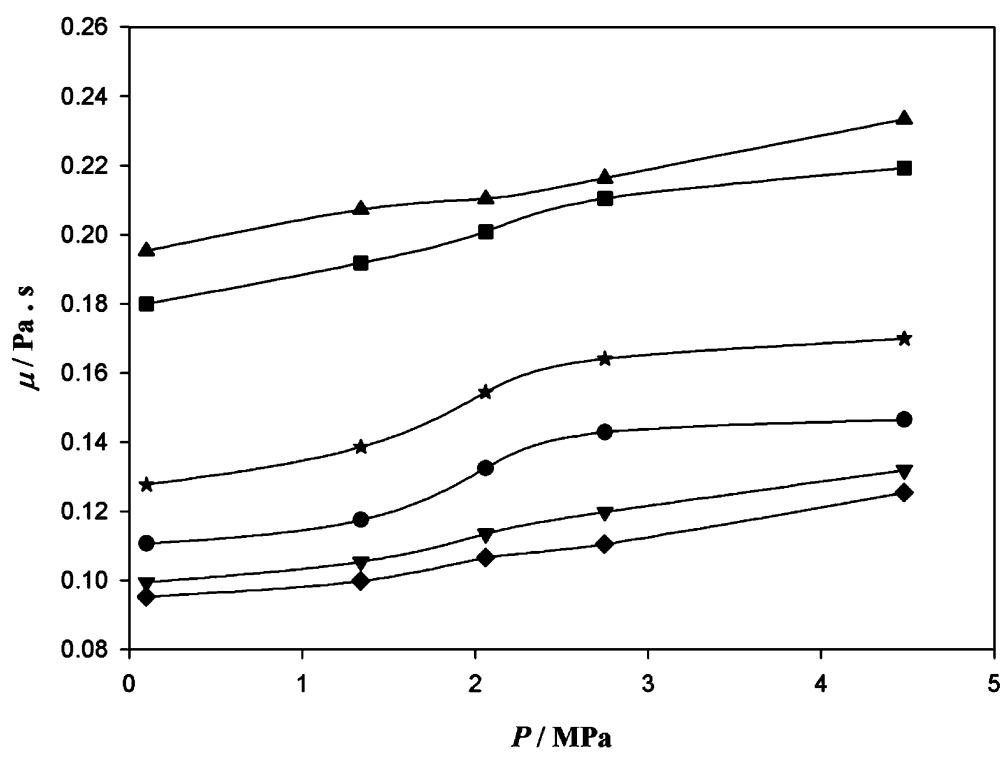

Figure 2. Experimental viscosity of nontraditional lightweight completion fluid as a function of pressure. $\Delta=25^{\circ} \mathrm{C} ; \boldsymbol{\square}=40^{\circ} \mathrm{C} ; \star=50^{\circ} \mathrm{C} ; \boldsymbol{\bullet}=70^{\circ} \mathrm{C} ; \boldsymbol{\nabla}=80^{\circ} \mathrm{C} ;=100^{\circ} \mathrm{C}$ ). 
As predicted, Figure 1 shows that viscosity of the fluid decreases with temperature. It is also observed that thermal energy causes an increase in the molecular distances due to the reduction of the intermolecular forces (Hassan and Hobani, 1998). Thus, when temperature is increased, this energy causes the rearrangement of particles in parallel directions and breaking them into smaller particles. The particles can move easily due to the reduction of intermolecular forces and particle-particle interaction. This causes viscosity to decrease.

Figure 2 shows a slight increase of fluid viscosity with pressure. The increase of pressure causes the molecules to be closer and decrease the space between them. Thus, it is harder for the fluid to move. However, viscosity change with pressure is not as significant with temperature. At low pressure, the effect of pressure to viscosity seems negligible. This is because the fluid is incompressible. Thus, more pressure is needed to compress the fluid and increase its viscosity.

To correlate the relationship between viscosity, pressure, and temperature, the measured experimental viscosities data were fitted to the modified of Mehrotra and Svrcek's (1987) equation. Mehrotra and Svrcek's equation is originally a modification of the equation proposed by Khan et al. (1984). It has been successfully been used to correlate the viscosity of specific non-Newtonian fluid with pressure and temperature. Puttagunta et al. (1993) used the equation to establish the relationship of bitumen viscosity to pressure and temperature.

Based on our previous study on the rheological behavior of the fluid, we found that the fluid is likely to follow pseudoplastic behavior, which can be expressed by the Mizhari-Berk equation (Khalil et al., 2010). Thus it is apparent that SLWCF is a nonNewtonian fluid. This information is essential to determine the best equation to predict viscosity as a function of pressure and temperature. As mentioned previously, the model of Mehrotra and Svrcek's equations has been successfully utilized to predict the correlation between viscosity, pressure, and temperature.

The selection of this model is based on its suitability to represent a dramatic decrement of viscosity value with the increase of temperature using a natural logarithmic function. In a study to predict the viscosity of Canadian bitumen, Puttagunta et al. (1993) introduced three different constants $\left(a_{1}, a_{2}\right.$, and $\left.a_{3}\right)$, which were obtained from regression constants for a linear relationship between logarithm of viscosity with pressure and the exponential term of temperature. However, in this study, to match the model and measured data, we modified the equation by eliminating the exponential factor of temperature. This modification was made because our fluid acts in a smaller magnitude compare to bitumen when it is subjected to temperature changes. In the case of bitumen, the viscosities of the fluid decrease dramatically with temperature. In SLWCF, the viscosity also decreased with temperature, but it is not as much as the increment in bitumen. It is reported that the viscosity of bitumen decreased as much as $99.15 \%$ when the temperature was increased from $37.4^{\circ} \mathrm{C}$ to $115.6^{\circ} \mathrm{C}$ (Puttagunta et al., 1993). Thus, in the previous study, they used an exponential term to express these rapid changes on bitumen viscosity. However, in our case, the reduction of the fluid viscosity was only $45.45 \%$. Thus an exponential factor in the temperature variable is no longer suitable to express this phenomenon.

In this study, to match the model, we modified the equation by eliminating the exponential factor. To determine the accuracy of the fitting, the experimental viscosity data was compared to the values derived from modification of Mehrotra and Svrcek's correlation. In addition, the sum of square error (SSE), $R^{2}$, adjusted $R^{2}$, and root mean square error (RMSE) were also determined. 
Table 2

Calculated empirical constants parameters and deviations of nontraditional lightweight completion fluid

\begin{tabular}{lcc}
\hline \multicolumn{1}{c}{ Parameters } & Value & $\begin{array}{c}95 \% \text { Confidence } \\
\text { interval }\end{array}$ \\
\hline$a_{1}$ & -1.359 & {$[-1.442,-1.276]$} \\
$a_{2}$ & 0.05859 & {$[0.0336,0.08359]$} \\
$a_{3}$ & -0.009573 & {$[-0.01083,-0.008314]$} \\
Sum of square error (SSE) & 0.2135 & - \\
$R^{2}$ & 0.908 & - \\
Adjusted $R^{2}$ & 0.9012 & - \\
Root mean square error (RMSE) & 0.08892 & - \\
\hline
\end{tabular}

Based on the fitting of experimental viscosity data to the modification of Mehrotra and Svrcek's equation, three empirical constants parameters were calculated and they are presented in Table 2, along with the SSE, $R^{2}$, adjusted $R^{2}$, and RMSE. Based on the results it shows that the model is deemed reliable to predict the interaction of viscosity with pressure and temperature. The value of $R^{2}$ and adjusted $R^{2}$ are close to 1; SSE and RMSE are considerably low. This indicates that it is possible to interpolate and predict the viscosity of the fluid at any pressure and temperature condition with the use of the modified Mehrotra and Svrcek Eq. (1).

Figure 3 shows the comparison of the fluid experimental viscosity values and predicted viscosity values calculated using the model at 2.06 MPa. All of the points lie

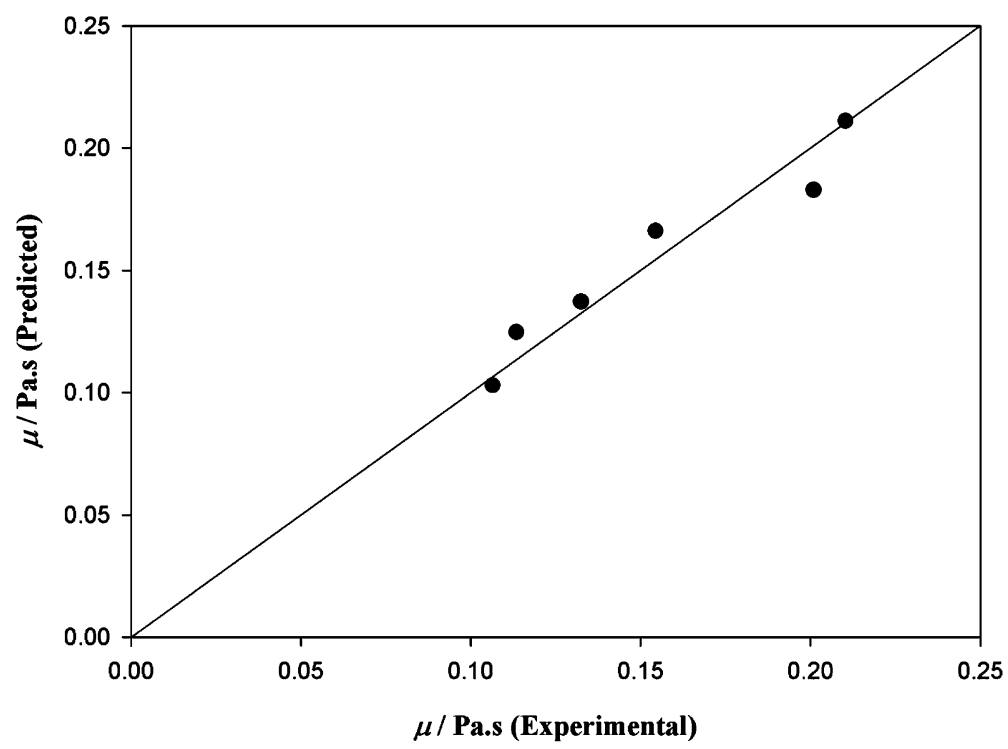

Figure 3. Comparison of experimental and predicted viscosities of nontraditional lightweight completion fluid at $2.06 \mathrm{MPa}$. 


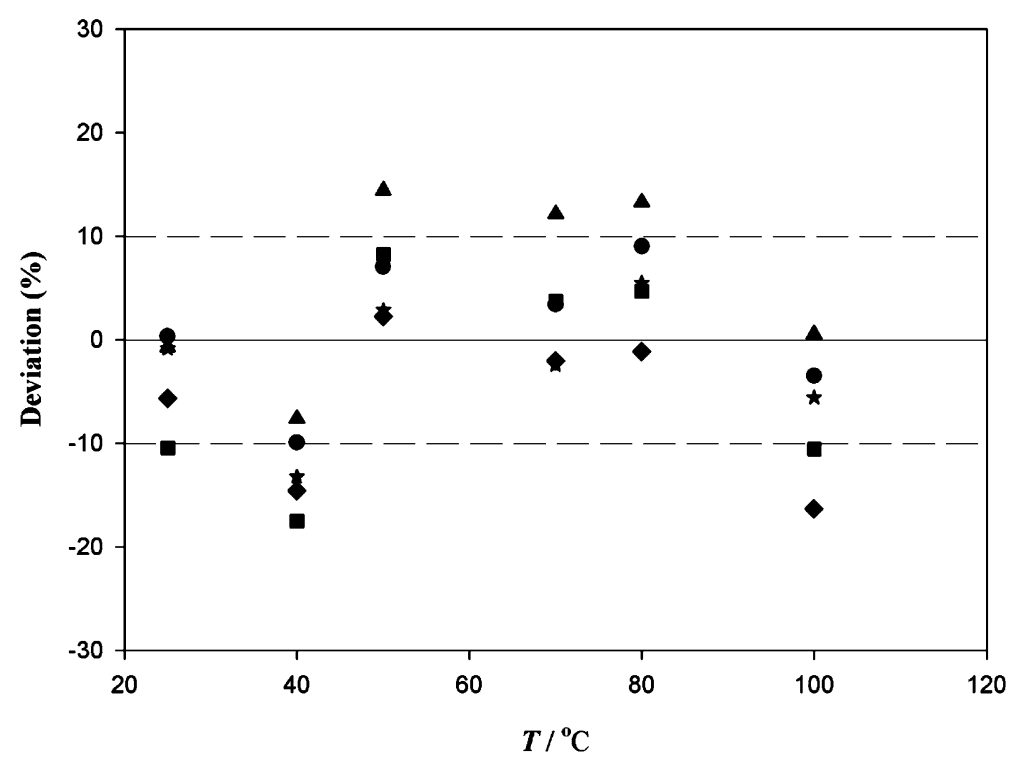

Figure 4. Deviation between experimental viscosity values and predicted viscosity values. $\mathbf{\square}=$ $0.1 \mathrm{MPa} ; \boldsymbol{\Delta}=1.34 \mathrm{MPa} ; \bullet=2.06 \mathrm{MPa} ; \star=2.75 \mathrm{MPa} \bullet=4.48 \mathrm{MPa} ;---=$ deviation at $\pm 10 \%$.

on the straight line indicating that the predicted values are in a good agreement with experimental data. In addition, the deviations between experimental and predicted values were also determined. The deviation was calculated as $100 *\left(1-\mu_{\text {Experimental }} / \mu_{\text {Predicted }}\right)$. Figure 4 presents the deviation between the fluid viscosities measured in the lab and calculated viscosities from the model. Based on the results, it shows that the predictions are in a good agreement with the experimental data. The deviation is in the range of $\pm 14 \%$.

In this study, the laboratory-based study to predict the SLWCF viscosity data on wide range of pressure and temperature results was also compared to field data in order to determine the accuracy and the applicability of the model to predict the behavior of the fluid once it apply in the field. To validate the accuracy of the model to predict the fluid behavior at field condition, viscosity value calculated with the model were compared with the viscosity value measured on the field condition. The accuracy was calculated and used to indicate whether the viscosity value calculated by the model is in good agreement with field data. Based on our previous study on field test at 2,058.3 m underground, the viscosity of SLWCF was recorded at $0.072 \mathrm{~Pa} \cdot \mathrm{sec}$ under the condition where the pressure was $2,000 \mathrm{psi}(13.78 \mathrm{MPa})$ and temperature was $240^{\circ} \mathrm{F}\left(115.55^{\circ} \mathrm{C}\right)$. At these conditions (pressure $=13.78 \mathrm{psi}$ and temperature $=115.55^{\circ} \mathrm{C}$ ), the viscosity value calculated using the model is $0.06758 \mathrm{~Pa} \cdot \mathrm{sec}$, with the calculated accuracy of $93.86 \%$ to the field viscosity value. Notice that based on the deviation value, it can be inferred that the model is in a good agreement both with laboratory and field data.

\section{Conclusions}

Viscosity values of nontraditional SLWCF have been measured at high pressure and temperature. Pressure and temperature varied from $25-100^{\circ} \mathrm{C}$ and $0.1-4.48 \mathrm{MPa}$, re- 
spectively. These viscosity data were then fitted to the modified form of Mehrotra and Svrcek's equation to correlate the relationship between viscosity, pressure, and temperature. It is found that the model is good to express and predict the interaction between viscosity, pressure, and temperature with SSE and RMSE values were 0.2135 and 0.08892 , respectively. In addition, the results also show that the predicted fluid viscosity values are in a good agreement both with the experimental data and field data with deviation in the range of $\pm 14 \%$ and $17.59 \%$, respectively.

\section{References}

Badrul, M. J., Rae, G. R., Noor, M. I., Suhadi, A. N., and Devadaas, M. (2009). Increasing production by maximizing underbalance during perforation using nontraditional lightweight completion fluid. SPE Drill. Complet. 24:326-331.

Bartusiak, R., Behrmann, L. A., and Halleck, P. M. (1997). Experimental investigation of surge flow velocity and volume needed to obtain perforation cleanup. J. Pet. Sci. Eng. 17:19-28.

Hassan, B. H., and Hobani, A. I. (1998). Flow properties of Roselle (Hibiscus sabdariffa L.) extract. J. Food Eng. 35:459-470.

Khalil, M., Badrul, M. J., and Aziz, A. R. (2010). Rheology of nontraditional lightweight completion fluid and its dependence on temperature. J. Petrol. Sci. Eng. 77:27-33.

Khan, M. A. B., Mehrotra, A. K., and Svrcek, W. Y. (1984). Viscosity models of gas-free Athabasca bitumen. J. Can. Pet. Tech. 23:47-53.

Mehrotra, A. K., and Svrcek, W. Y. (1987). Viscosity of compressed cold lake bitumen. Can. J. Chem. Eng. 65:672-675.

Puttagunta, V. R., Singh, B., and Miadonye, A. (1993). Correlation of bitumen viscosity with temperature and pressure. Can. J. Chem. Eng. 71:447-450. 